Agro-Science Journal of Tropical Agriculture, Food, Environment and Extension Volume 8 Number 2 Mav 2009 pp 130-138

ISSN 1119-7455

\title{
IMPLICATIONS OF POLYEMBRYONY ON THE GROWTH AND YIELD OF FLUTED PUMPKIN (Telfairia occidentalis HOOK. F.)
}

\author{
Onovo ${ }^{1}$ J. C. Uguru' ${ }^{2}$ M. I. and $\mathrm{Obi}^{3}$ I.U. \\ ${ }^{1}$ Department of Biological Sciences, Nasarawa State University, Keffi, \\ Nasarawa State, Nigeria. E-mail: onovojos@yahoo.com \\ ${ }^{2}$ Department of Crop Science, University of Nigeria, Nsukka, Nigeria. \\ ${ }^{3}$ Department of Crop Science, University of Nigeria, Nsukka, Nigeria.
}

\begin{abstract}
Two experiments were conducted during the wet seasons of 2004 and 2005 to investigate the performance of polyembryonic lines with respect to growth and yield of fluted pumpkin. The results revealed three morphotypes of polyembryony, namely: twin (bi-embryony), triple (tri-embryony) and quadruple (tetra-embryony). In the first year (2004), the triple and quadruple embryo types had the highest (54.52\%) and lowest (2.02\%) frequencies of occurrence, respectively. In the second year (2005), the frequencies of the triple and quadruple embryo types were 60.99\% and $4.78 \%$, respectively. There was no clear trend across all the embryo types investigated with respect to the characters measured. However, generally, the triple and the single (mono-embryony) lines performed better than the twin and quadruple lines. The impressive performance of the single and triple embryo types over the twin and quadruple embryo types with respect to the weight of pods, in 2004 and 2005 suggests that these embryo types are good candidates multiplication and distribution to farmers using the micropropagation technique.
\end{abstract}

Key words: Polyembryony, growth, yield, fluted pumpkin, Telfairia occidentalis.

\section{INTRODUCTION}

The fluted pumpkin (Telfairia occidentalis Hook. F.) belongs to the family cucurbitaceae, which consists of 90 genera and 750 species (Irvine,1969; Purseglove, 1984). It is one of the most widely cultivated leafy vegetables in southern Nigeria (Odiaka et al., 2008). Asiegbu (1987) reported protein and oil contents of the seed at 30.1 and $47 \%$, respectively. He also reported that the essential amino acid content compared favourably with those of important legumes such as soybean and groundnut. The plant could also find potential use in medicine since the roots and older leaf extract contain compounds such as resins, alkaloids and saponins (Akubue et al., 1980). It could also be exploited as a cover crop along with melon (Colocynthis vulgaris) in vegetable farms of Okra (Abelmoschus esculentus) and Pepper (Capsicum annum) (Akobundu, 1987).

One characteristic feature of fluted pumpkin is its exhibition of the polyembryonic trait. Different forms of polyembryony have been reported to occur in T.occidentalis
(Odiyi, 2003). The author suggested that the occurrence of polyembryony is natural and that multiple seedlings were observed to develop in two areas of the seeds of the crop. The occurrence of multiple embryos in the embryonic axis and cotyledons makes it possible to obtain more plants from one seed as suggested by Esiaba (1982). This may help to overcome shortage of planting materials However, the seedlings are likely to be similar in all respects because of the post-zygotic and post-germinal nature of the emerging embryos (Odiyi, 2003). In addition, seedlings emerging from the cotyledons can serve as substitutes where zygotic embryos or seedlings are poorly developed or damaged during germination. Guo et al. (2006) reported that polyembryony and male/female sterility are two reproductive difficulties that have greatly hampered the improvement of Citrus by conventional sexual breeding. Sedgely and Griffing (1989) reported that polyembryony is under genetic control in some fruit tree crops. For instance, in Irvingia gabonensis, the level of polyembryony was 
found to differ among accessions collected worldwide. Accessions that showed polyembryony in Ibadan also showed high levels of polyembryony in M'Balmayo, Onne and Ibadan, indicating that it is probably an inherited characteristic in the accessions exhibiting this trait. Assessment of six kernels from a polyembryonic fruit was about equivalent to the weight of the single kernel of normal fruit from the same accession. Therefore, from a production point of view, there seems to be little reason to select for this characteristic.

The occurrence of multiple seedlings has led to questions as to the type, frequency, benefits and morphotypes of such a trait. The present research was initiated to investigate the forms and benefits or otherwise of the polyembryonic lines through their performance in the field, and provide useful information to farmers who grow fluted pumpkin.

\section{MATERIALS AND METHODS}

The experiments were conducted at the laboratory and research farms of the Department of Crop Science, Faculty of Agriculture, University of Nigeria, Nsukka. Nsukka is located at Latitude $6{ }^{0} 52^{1} \mathrm{~N}$, Longitude $7^{0} 24^{1} \mathrm{E}$, and on Altitude of $447.2 \mathrm{~m}$, in the derived guinea savanna region of Nigeria. Twenty eight fluted pumpkin pods were collected from the research farm of the University of Nigeria, Nsukka, at the end of the growing season in 2003 and carefully preserved. At the beginning of the rainy season in 2004, the pods were split open and the seeds extracted and cleaned of the perispermic tissues. The seeds were pre-sprouted in a nursery medium consisting of well cured softwood sawdust. Watering was done on daily basis until the seeds started to sprout.

As soon as the cotyledons split open, the seeds were removed from the medium and their cotyledons were carefully examined with a hand lens for the number of emerging embryos. The seedlings of each of the four embryonic types observed (i.e. single, twin, triple and quadruple) were replanted in separate nursery boxes. The seedlings were transplanted at two weeks after planting.

The experimental design was a Randomized Complete Block Design (RCBD) with three replications. The single (monoembryony), twin, triple and quadruple embryos constituted the four (4) treatments. A portion of land measuring $83 \mathrm{~m}$ x $24 \mathrm{~m}\left(1992 \mathrm{~m}^{2}\right)$ was slashed, ploughed, harrowed and marked out into three blocks. Each block was divided into four (4) plots. A foot path was allowed between blocks.

A total of 1,836 pre-sprouted seedlings from the 28 pods were planted at a spacing of $1 \mathrm{~m} \times 1 \mathrm{~m}$. Each of the four plots consisted of 80,120, 250 and 9 seedlings of single, twin, triple and quadruple embryo types, respectively. Plots were labelled accordingly following random treatment allocation for ease of identification of the treatments. N-P-K, 15: 15: 15 fertilizer at the rate of $300 \mathrm{~kg} \mathrm{ha}^{-1}$ was applied four weeks after planting, according to Akoroda (1990). Weeding operation was carried out regularly as required. At the beginning of the rainy season in 2005, fresh seedlings from the seeds of the 2004 harvest were examined and the distribution of the different embryonic types were recorded. Numerical counts were made for the different embryonic forms and the number of the embryo types in the populations of fluted pumpkin were recorded. Similar experimental design, fertilizer application and cultural practices done in 2004 were carried out in 2005 , using a total of 1,151 pre-sprouted seedlings. Each of the four plots consisted of 37, 61, 176 and 14 seedlings of single, twin, triple and quadruple embryo types, respectively.

Data on number of leaves at 4 and 8 weeks after planting, length of longest vine at 4 and 8 weeks after planting, number of branches at 4 and 8 weeks after planting, and fresh weight of pods per treatment at maturity of the different embryonic types were collected. The field data were subjected to analysis of variance according to Steel and Torrie (1980). The separation of treatment means for statistical significance was done using F-LSD according to Obi (1986).

\section{RESULTS}

Polyembryony in Telfairia occidentalis was expressed in three forms, namely twin, triple and quadruple. Plate 1 shows mono-embryony (1A) and the three morphotypes of polyembryony (1B, C and D). The results of the frequencies of the single and polyembryonic embryo types in 2004 and 2005 are presented in Table 1. The triple and the quadruple embryo types had the highest $(54.52 \%)$ and lowest $(2.02 \%)$ frequencies of occurrence, respectively. Similar results were obtained 
Table 1: Frequencies of the single and polyembryonic embryo types in 2004 and 2005.

\begin{tabular}{|c|c|c|c|c|c|c|c|c|c|}
\hline Embryo type & \multicolumn{2}{|l|}{$\mathbf{S}$} & \multicolumn{2}{|l|}{$\mathbf{T w}$} & \multicolumn{2}{|l|}{$\mathbf{T r}$} & \multicolumn{2}{|l|}{$\mathbf{Q}$} & \multirow[t]{2}{*}{ Total } \\
\hline & No & $\begin{array}{l}\mathrm{F}( \\
\%)\end{array}$ & No. & $\begin{array}{l}\mathrm{F}( \\
\%)\end{array}$ & No. & $\begin{array}{l}\mathrm{F}( \\
\%)\end{array}$ & No. & $\begin{array}{l}\mathrm{F}( \\
\%)\end{array}$ & \\
\hline Year & & & & & & & & & \\
\hline$\overline{2004}$ & 319 & 17.37 & 479 & 26.09 & 1001 & 54.52 & 37 & 2.02 & 1836 \\
\hline 2005 & 150 & 13.03 & 244 & 21.20 & 702 & 60.99 & 55 & 4.78 & 1151 \\
\hline $\begin{array}{lll}\mathbf{S}- & \text { Single } \\
\mathbf{T w}- & \text { Twin } \\
\mathbf{T r}- & \text { Triple } \\
\mathbf{Q}- & \text { Quadr }\end{array}$ & $\begin{array}{l}\text { yo ty } \\
\text { yo ty } \\
\text { yo ty } \\
\text { embr }\end{array}$ & type & & & & & & & \\
\hline
\end{tabular}

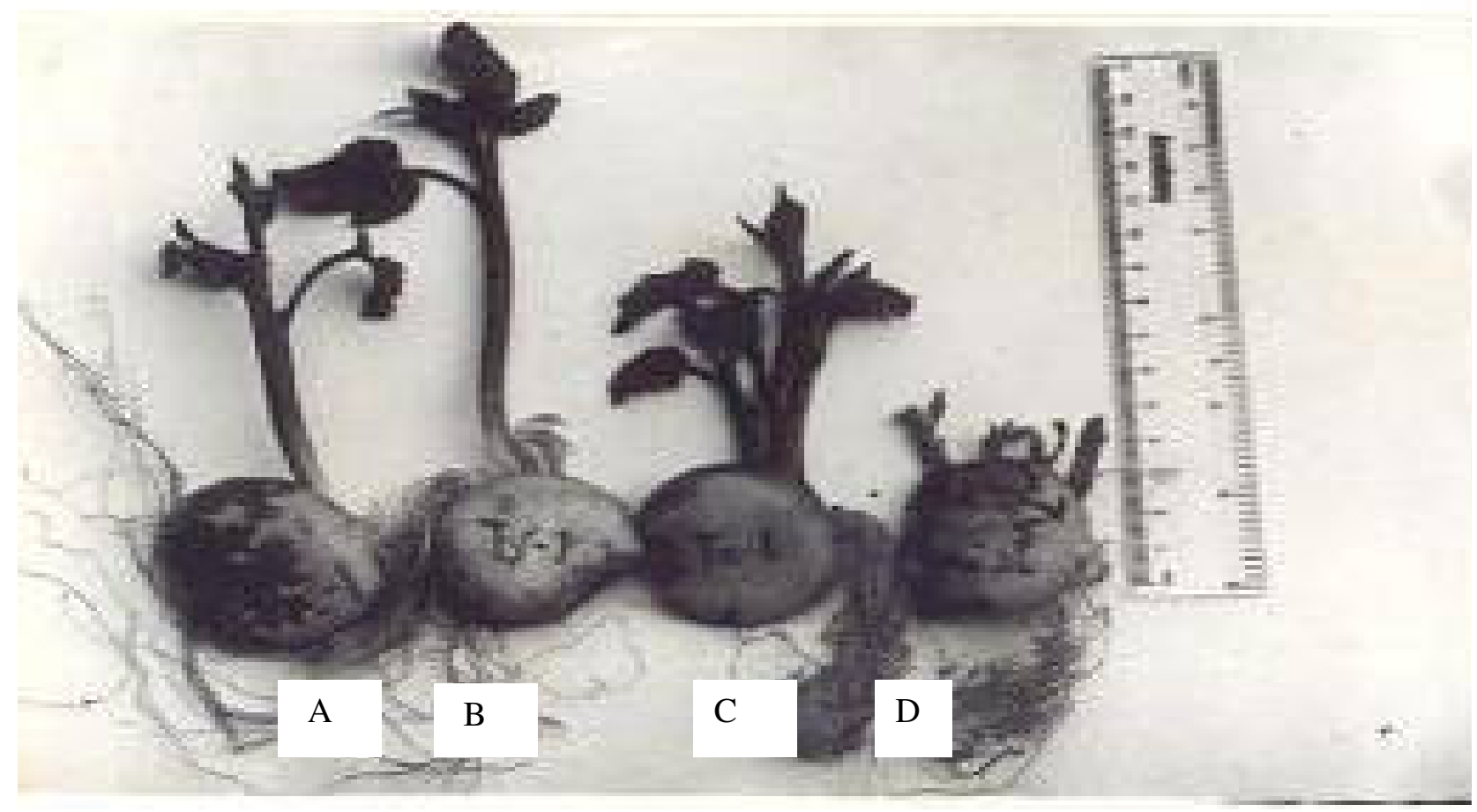

Plate 1. Single and three morphotypes of polyembryony: A (Single), B (Twin), C (Triple) and D (Quadruple

in 2005 with the triple type giving $60.99 \%$ and quadruple $4.78 \%$.

The results of the effect of embryo type on number of leaves at 4 weeks after planting (WAP) for 2004 and 2005 are presented in Fig. 1. The results revealed that the embryo types performed better in 2005 than in 2004 with respect to number of leaves. In 2004, single, triple and quadruple were comparable and differed significantly $(\mathrm{P}<0.05)$ from twin which produced lower number of leaves. In 2005, single and twin were comparable and differed significantly $(\mathrm{P}<0.05)$ from triple and quadruple.
At 8 WAP in 2004, single embryony produced significantly higher number of leaves (Fig. 2). As the number of embryos increased, there was a concomitant reduction in the number of leaves. However in 2005, though twin produced lower number of leaves at 8WAP than the other embryo types, the trend appears to be the reverse of the result obtained in 2004, hence, there was a concomitant increase in the number of leaves as the number of embryos increased at 8 WAP.

Figure 3 shows the effect of embryo type on vine length at 4WAP in 2004 and 2005. In 2004, twin and triple 
were comparable but were significantly ( $\mathrm{P}$ $<0.05)$ lower than single and quadruple which produced longer vines. In 2005, single, twin and triple had comparable values, and they differed significantly $(\mathrm{P}<$ $0.05)$ from the quadruple which had the highest value of vine length. At 8 WAP in 2004 (Fig. 4), twin and triple were comparable and differed significantly $(\mathrm{P}<$ 0.05) from single and quadruple which had the highest and lowest values, respectively. In 2005, single and triple were comparable and differed significantly $(\mathrm{P}<0.05)$ from twin and quadruple which had comparable but higher values of vine length.

The results of the effect of embryo type on the number of branches at 4 and 8WAP are presented in Figs. 5 and 6, respectively. In 2004 at 4WAP, single and twin had equal mean number of branches that differed significantly $(\mathrm{P}<0.05)$ from the number of branches of triple and quadruple which also had equal number of branches. However, in 2005, all the embryo types performed better with respect to the number of branches than in 2004, although, single, twin and triple had comparable values that differed significantly $(\mathrm{P}<0.05)$ from quadruple which had the highest number of branches. The results obtained at 8WAP showed a consistent decrease in vine length with increase in the number of embryos in 2004. However, in 2005, all the embryo types differed significantly from one another with respect to mean number of branches at $8 \mathrm{WAP}$.

Figure 7 shows the mean weight of pods per plant of the embryo types in 2004 and 2005. In 2004, single and triple were comparable and performed better than twin and quadruple. They also differed significantly $(\mathrm{P}<0.05)$ from twin and quadruple. In 2005, similar results were obtained with respect to weight of pods per plant.

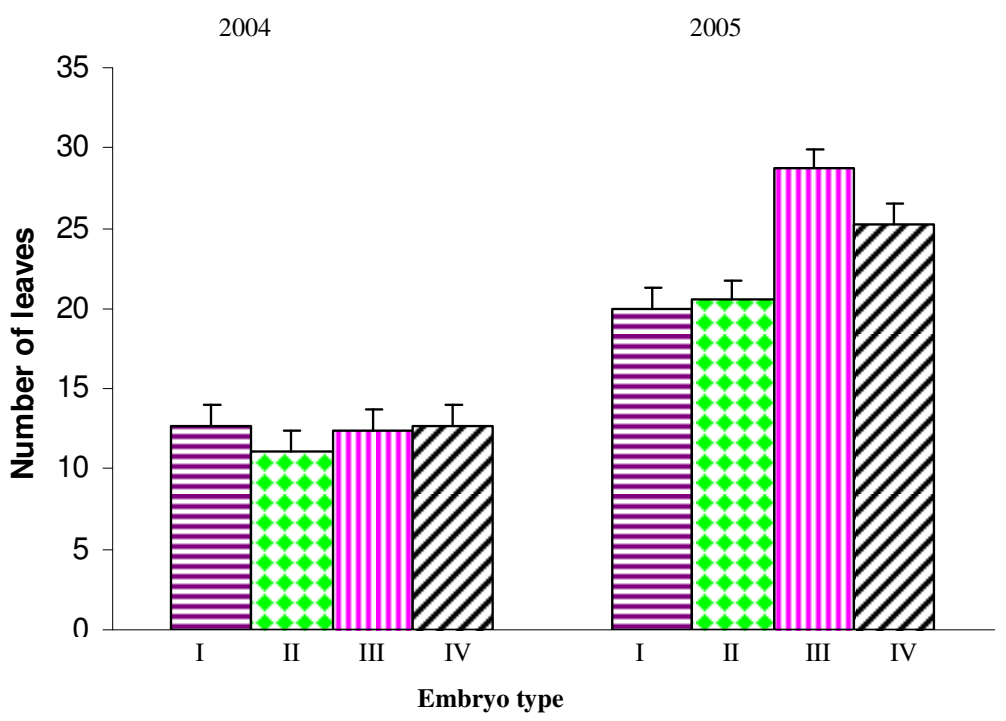

日 I.Single embryo $\square$ II. Twin embryo ๑ III.Triple embryo 口 IV.Quadruple embryo

Fig 1:Effect of embryo type on number of leaves at 4 WAP in 2004 and 2005 


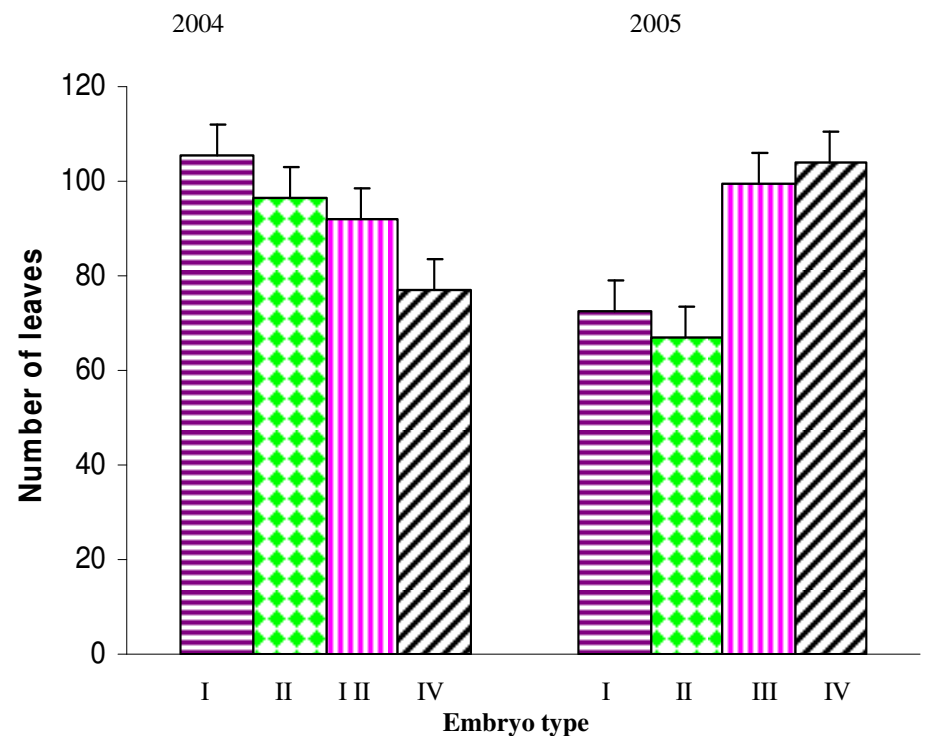

曰 I.Single embryo

$\checkmark$ Il. Twin embryo

๑ III.Triple embryo

$\checkmark$ IV.Quadruple embryo

Fig 2:Effect of embryo type on number of leaves at 8 WAP in 2004 and 2005

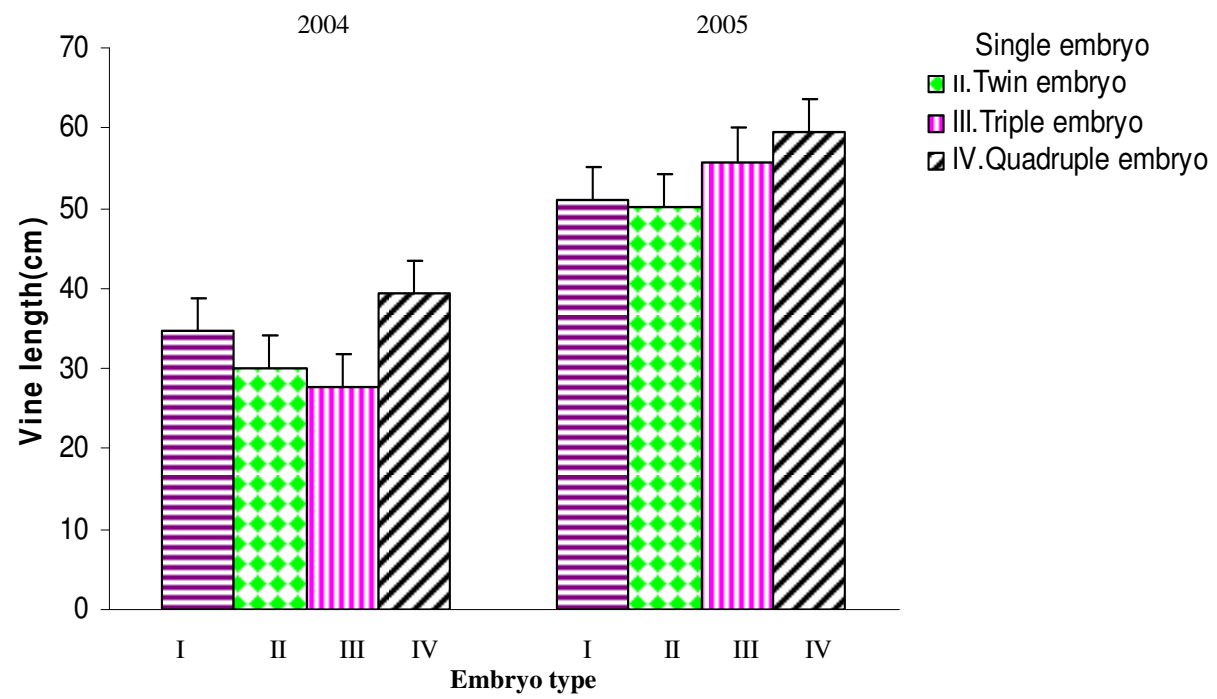

Fig. 3:Effect of embryo type on vine length at 4 WAP in 2004 and 2005 


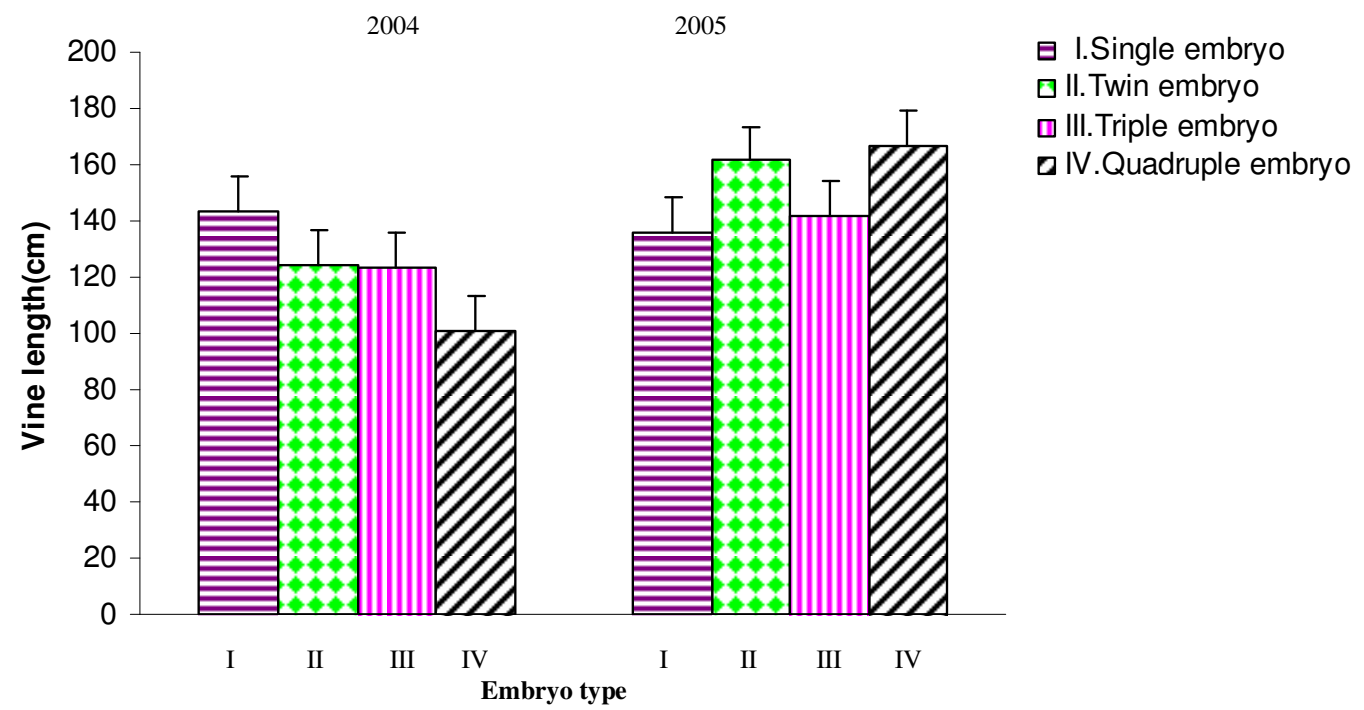

Fig 4:Effect of embryo type on vine length at 8 WAP in 2004 and 2005

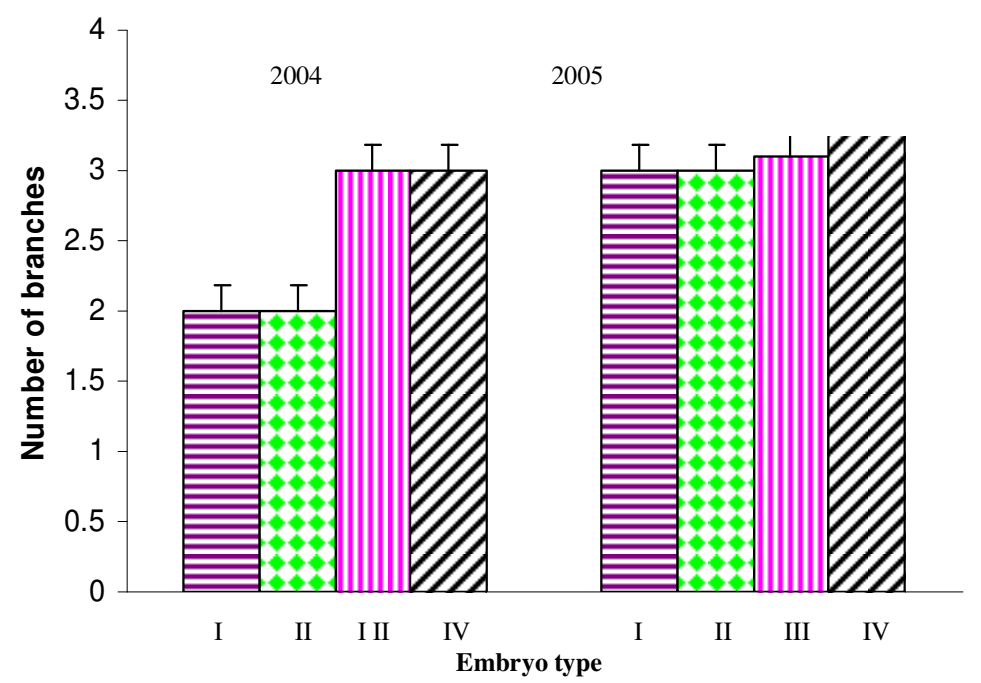

日 I.Single embryo
$\square$ II.Twin embryo
$\square$ III.Triple embryo
$\square$ IV.Quadruple embryo

Fig 5:Effect of embryo type on number of branches at 4 WAP in 2004 and 2005 
Onovo J. C. Uguru M. I. and Obi I..U.

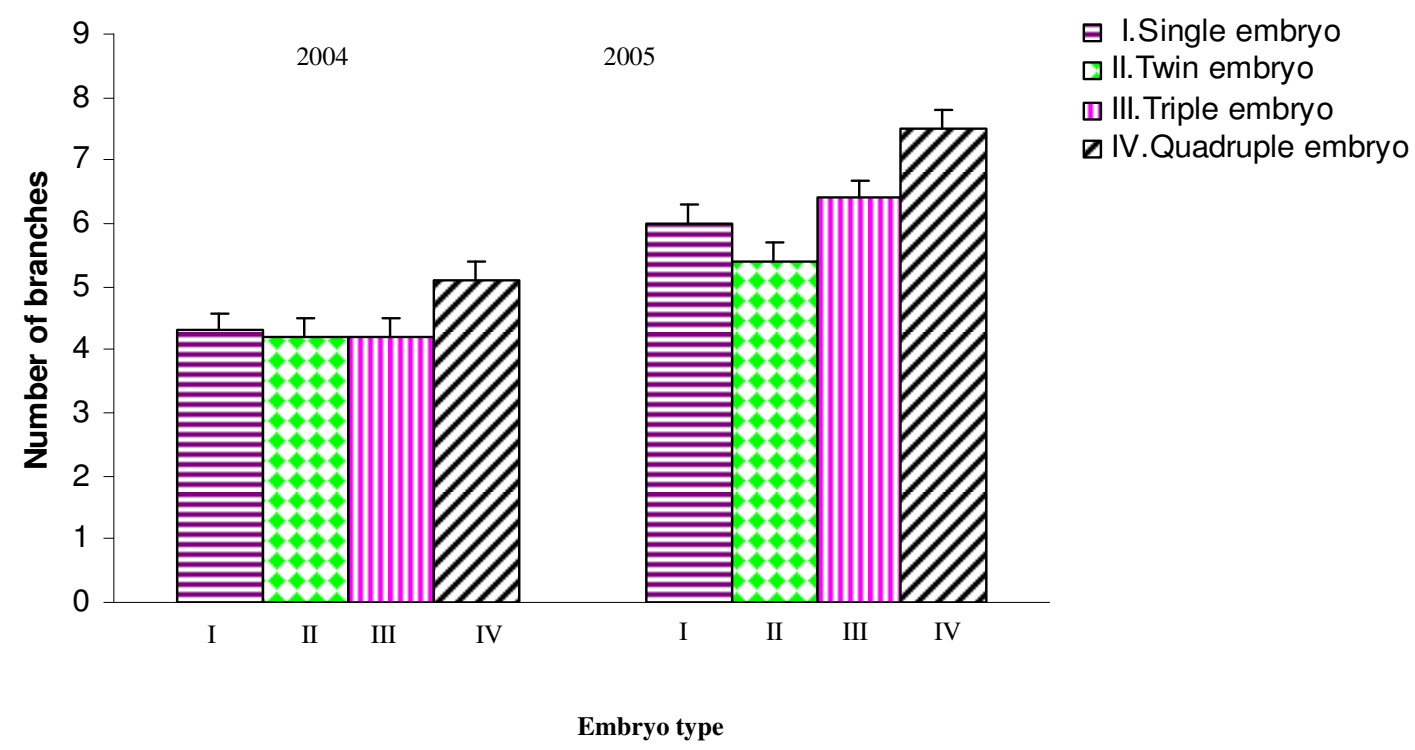

Fig 6:Effect of embryo type on number of branches at 8 WAP in 2004 and 2005

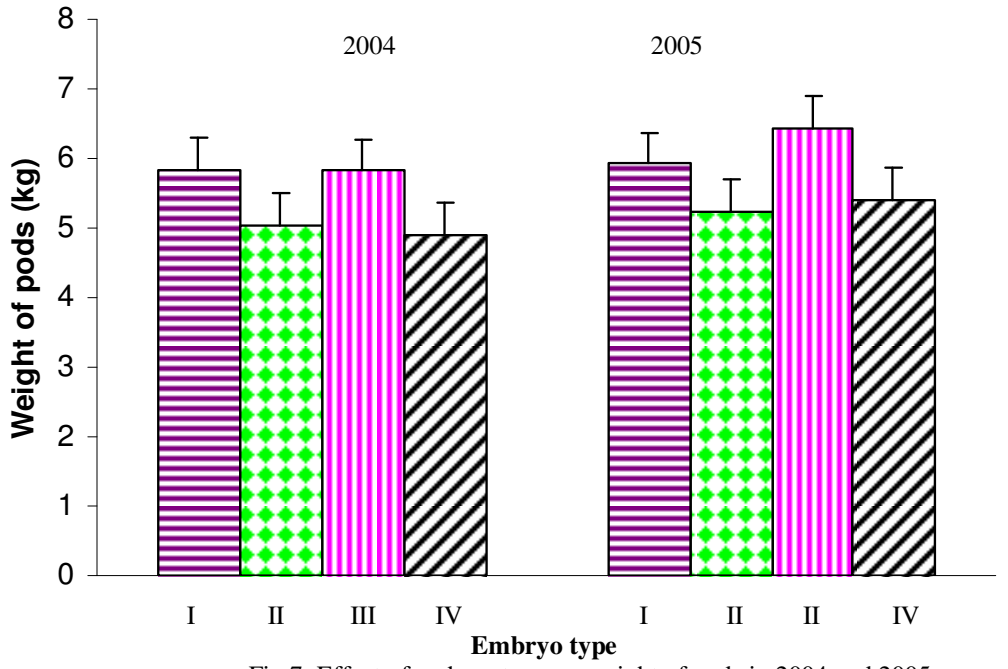

ㅂ I.Single embryo

$\square$ II. Twin embryo

口 III.Triple embryo

口 IV.Quadruple embryo

Fig 7: Effect of embryo type on weight of pods in 2004 and 2005

\section{DISCUSSION}

The expression of the three morphotypes of polyembryony (twin, triple and quadruple) and the single embryo type in 2004 and 2005 implies that these traits are heritable and occur at different frequencies. The consistent high and low frequencies of occurrence of the triple and the quadruple embryo types suggests that in any fluted pumpkin pod, there are likely to be more seeds that will exhibit tri-embryony than any other embryo type, while only a few seeds will have more than the triple embryos.
There was no clear trend across all the embryo types with respect to all the characters measured in 2004 and 2005. The inconsistency in the performance of the different embryo types might be due to the dioecious nature of the crop. This finding agrees with Pemberton (2001), who reported that varietal purity will be difficult to maintain in the crop because it is a cross pollinated crop.

The production of lower number of leaves by the twin embryo type than the other embryo types at 4WAP in 2004, could be as a result of a positive synergistic effect among the 
embryos of the triple and quadruple embryo types with respect to number of leaves at that age. This implies that genetic heterogeneity of the seeds that resulted in triple and quadruple embryo types have initial cells of sexual embryos that positively encouraged production of leaves. According to Batygina and Vinogradova (2007), genetic heterogeneity is one of the most important characteristics of seeds, which is based on different phenomena, such as embryologeny, embryoidogeny, and gametophytic and sporophytic apomixes. However, in 2005, the number of leaves produced by the twin embryo type was comparable to the number of leaves produced by the single embryo type. The concomitant reduction in the number of leaves with increase in the number of embryos at 8WAP in 2004 could be as a result of competition for nutrients, especially among the polyembryonic plants that developed side shoots which grew together with the main shoot.

The inconsistency in the performance of the embryo type with respect to the number of leaves at both 4 and 8 WAP in 2004 and 2005 implies that the expression of the genetic potentials of the different embryo types as regards leaf production must be carefully maintained through vegetative propagation (vine cuttings) or tissue culture techniques. Propagation of such fluted pumpkin lines through tissue culture could find applications in clonal propagation for achieving mass and cheap multiplication using the methods proposed by Levin et al (1988) and Okonkwo (1997); phytosanitation through meristem culture (Kassanis, 1957; Ng, 1991); micropropagation through callus and embryogenesis (Sharp et al., 1982) and protoplast culture (Pierik, 1987). This is in agreement with the report of Esiaba (1982) that polyembryonic trait in $T$. occidentalis would serve a good and economical means of clonal multiplication following successful selection of desired trait.

The impressive performance of quadruple embryo type with respect to length of vine at 8 WAP in 2004 and 2005 could be due to the degeneration of the weaker side shoots and the subsequent mobilization of the available assimilates for the support of the surviving shoot. According to Bidinger et al. (1996), variety reponse rate is controlled by the genetic potential of a variety. The authors reported that the stability of yield production depends on the ability of a variety to respond to environmental conditions.

The number of branches increased significantly with increase in the number of shoots of some of the embryo types in 2004 and 2005. The result at 4WAP for quadruple and to a large extent, triple is consistent with that of 8WAP, with respect to number of branches. Therefore, it is reasonable to assume that adoption of a proper cutting management practice on the polyembryonic lines will result in a better performance with respect to other characters such as number of leaves, vine length and weight of pods. Asiegbu (1985) reported that higher leaf yields with frequent harvest schedules was mostly due to greater branching resulting from more frequent removal of apical dominance with cutting of the terminal buds, which allowed for more flushes and for better and regular timing for taking advantage of new flushes following harvest. Mica (1986) also reported proliferation of branches with frequent defoliation of other vegetable crops. Bagust (1992) reported that pruning improves the quantity and quality of vegetable crops. The author also noted that increase in vegetative growth and fruit formation will be encouraged if vegetable crops are pruned. He suggested that pruning will assist in the removal of dead parts, thereby encouraging aeration and greater access to light.

The impressive performance of the single and triple embryo types over the twin and quadruple embryo types as regards to the weight of pods, in 2004 and 2005 suggests that these embryo types are good candidates for vegetative and micropropagation techniques for pod production in $T$. occidentalis. This finding is in contrast to the report of Sedgely and Griffing (1989) on Irvingia gabonensis (Bush mango). The authors reported that the assessment of six kernels from a polyembryonic fruit was about equivalent to the weight of the single kernel of normal fruits from the same accession. They concluded that from a production point of view, it will be unnecessary to select for the polyembryonic trait.

In general, with respect to agronomic value of polyembryony in fluted pumpkin, it could be concluded that the inconsistency in the performance of the different embryo types might be due to the dioecious nature of the crop. However, the triple and single lines were more impressive when compared with the twin and quadruple lines, especially with respect to weight of pods. Thus, the triple and single lines are promising and can be advanced further as possible candidates for clonal multiplication for desired traits like optimum leaf and pod production.

It is hoped that the application of tissue culture technique or successful vegetative propagation technique in large scale production 
of the promising embryo types will result in a remarkable increase in the supply of nutrient rich fluted pumpkin leaves and pods. To a large extent, this will help to overcome the difficulty in maintaining varietal purity due to the dioecious nature of fluted pumpkin.

\section{REFERENCES}

Akobundu, I.O. (1987). Weed Science in the Tropics. John Widely and Sons Ltd. $522 \mathrm{pp}$.

Akoroda, M.O. (1990). Seed production and breeding potential of fluted pumpkin (Telfairia occidentalis). Euphytica 49: 25-32.

Akubue, P. I., Kar, A. and Nnachetta, F.N. (1980) Toxicity of extracts of roots and leaves of Telfairia occidentalis. Planta Medica. 38: 339-343

Asiegbu, J.E. (1985). Characterization of Sexes in Fluted Pumpkin: Growth aand Yield in the Male and Female Sexes. Horticultural Science 50 (6): 251- 255.

Asiegbu, J.E. (1987). Some biochemical evaluation of fluted pumpkin seeds. $J$. Sci Food Agric. 40: 152-155.

Bagust, H. (1992). The ardener's Dictionary of Horticultural Terms. 245pp.

Batygina, T. and Vinogradova, G. (2007). Phenomenon of Polyembryony. Genetic heterogeneity of seed. Russian Journal of Developmental Biology. 38 (3) 126 -151.

Bidinger, F. R., Hammer, G. L. and Muchow, R. C. (1996). The physiological basis of genotype by environment interaction in crop adaptation. In: Plant Adaptation and Crop Improvement. CAB International. pp 329-348.

Esiaba, R.O. (1982). Cultivating the fluted pumpkin in Nigeria. World Crops, March/April. 70-72.

Guo, W. W., Chang, Y. J., Chen, L. C. and Deng, X. X. (2006). Molecular analysis revealed autotetraploid, diploid and tetraploid hybrid plants regenerated from an interspecific somatic fusion in Citrus. Scientia Horticulturae 108:162-166.

Irvine, F.R. (1969). West African Crops, Oxford University Press. 272pp.

Kassanis, B. (1957). The use of tissue culture to produce virus-free clones from infected potato varieties. Ann. Appl. Biol. 45: 447-450.
Levin, L., Gaba, V., Tai, B., Hirsh, S., DeNola, D. and Vasil, I. K. (1988). Automated plant tissue culture for mass propagation. Bio/Technology 6:1035-1040.

Mica, A. (1986): Physiological responses of fruit trees to pruning. Horticultural Rev. 8: 337-378.

Obi, I.U. (1986). Statistical methods of detecting differences between treatment means. Department of Crop Sc., UNN, Nigeria, pp 1-45

.Odiyi, A.C. (2003). Developmental patterns of the multiple seedling trait in Telfairia occidentalis Hook.f. J. Sustain Agric. Environ. 5(2): 319-325.

Okonkwo, S. Y. C. (1997). Modern crop manipulations for increased productivity. Paper presented at the International Conference on "Biotechnology for Development in Africa: Priorities for the early $21^{\text {st }}$ century" organized by FADIB, Enugu, Nigeria.

Ng, S. Y. C. (1991). In vitro conservation and distribution of root and tuber crop germpasm. Proc. Int. Conf. on Crop Genetic Resources of Africa, 17-20 October, Ibadan, Nigeria. pp. 95-106.

Odiaka, N. I.; Akoroda, M. O. and Odiaka, E. C. (2008). Diversity and production methods of fluted pumpkin (Telfairia occidentalis Hook. f.); Experience with vegetable farmers in Markurdi, Nigeria. African Journal of Biotecnology 7 (8): 944-954.

Pierik, R. L. M. (1987). In vitro Culture of Higher Plants. Martinus Nijhoff Publisher's Group, Dordrecht, 344pp.

Pemberton, R.W. (2001). Finding and Fruiting the Fluted Pumpkin. The Cucurbit Network. 8(1): 1-3.

Purseglove, J.W. (1984). Tropical Crops. Dicotyledons. Volumes 1 and 2. English Language Book Society and Longmans, London. p 100.

Sedgely, M. and A. R. Griffing (1989). Sexual reproduction of tree crops Academic press, Sydney, Australia 378pp.

Sharp, W. R., Evans, D. A. and Sondahl, M. R. (1982). Applications of somatic embryogenesis to crop improvement. Proc. $5^{\text {th }}$ Int. Cong. Plant Tissue Culture, Tokyo, Japan (A. Fujiwara, ed.) pp. 759-762.

Steel, G. D. and J. H. Torrie (1980). Principles and Procedures of Statistics: A Biometrical Approach. $3^{\text {rd }}$ edition. Hill Book Company Inc.New York. 633pp. 